\title{
Influence of Rotor Endcaps on the Electromagnetic Performance of High Speed PM Machine
}

\author{
Ahmed Al-Timimy ${ }^{1}$, Mahir Al-Ani ${ }^{1}$, Michele Degano ${ }^{1,2^{*}}$, Paolo Giangrande ${ }^{1}$, Chris Gerada ${ }^{1,2^{*}}$, \\ Michael Galea ${ }^{1,2^{*}}$ \\ ${ }^{1}$ Department of Electrical and Electronic Engineering, University of Nottingham, University Park, Nottingham \\ NG7 2RD, UK \\ ${ }^{2}$ Department of Electrical and Electronic Engineering, University of Nottingham - Ningbo China, Ningbo, China \\ *Ahmed.Al-Timimy@nottingham.ac.uk
}

\begin{abstract}
Surface-mounted permanent magnet (SPM) machines are preferred for high-speed aerospace applications over induction and switched reluctance machines, since they combine the advantages of high torque density and efficiency. Also, in aerospace applications, where low rotor weight and inertia are essential requirements, a permeable hollow shaft is proposed to replace the need for rotor back-iron and reduce the overall rotor weight. For rotor mechanical integrity, a retaining sleeve is commonly used, leading to thicker magnetic airgap. Furthermore, when permeable rotor endcaps are applied, an increase of the magnetic end leakage occurs, i.e. end-effect. In this paper, the influence of the rotor endcaps on the mechanical and electromagnetic performance of a high-speed SPM machine is investigated through 3D-finite element analyses (FEA). Also, different endcap thickness and different rotor shaft materials are investigated and compared in this work. Finally, a prototype of the SPM machine under study has been manufactured and tested. The comparison between simulation and experimental results is presented and discussed.
\end{abstract}

\section{Introduction}

High-speed electrical machines have been developed for many industrial applications, including turbochargers, turbo-compressors, engine electrification and aerospace [1]. These machines are asked to fulfil challenging electromagnetic and mechanical requirements at high temperature and high-speed operating conditions. In terms of power density, surface-mounted permanent magnet (SPM) machines are considered the most suitable candidates for such applications. Indeed, compared to induction, switched and synchronous reluctance machines they present higher torque density, lower electromagnetic losses and a rotor of acceptable mechanical integrity [2]. Usually, rotors with a permeable hollow shaft are commonly used, in order to fulfil low weight and inertia requirements, especially in aerospace applications. The permeable material used for the shaft performs the same magnetic function of the rotor back-iron, while ensures mechanical strength. For high speed applications, a retaining sleeve and rotor endcaps are mandatory to guarantee the rotor mechanical integrity. However, the retaining sleeve leads to a larger magnetic airgap, while the presence of permeable rotor endcaps increases the leakage flux at the front and back ends of the rotor. These end-effects lead to a reduction in the electromagnetic performance and therefore needs to be taken into account during the design stage [3]-[6].

Analytical methods for modelling end-effect are proposed in [7], [8], while a lumped parameter circuit is used in [9], for modelling the flux leakage paths in the end-region. The above methods can predict results relatively quickly, but with some limitation in terms of accuracy due to the assumptions on which they are built. Therefore, when a high confidence in the results is needed, the use of 3D-fininte element analysis (FEA) becomes mandatory despite the well- known drawback of higher computational time. The influence of the end-effect on the electromagnetic performance has been investigated in several PM machines [10-17]. In [10], the end-effect in IPM and SPM machines is investigated. An analytical model of a SPM machine including the magnetic saturation and end-effect is presented in [11]. Moreover, 3DFEA and 2D-FEA results of doubly salient machine are compared in order to examine the end-effect influence [12], [13]. A 3D-model of SFPM machine is developed and analyzed using lumped parameter circuit and 3D-FEA, and validated by experiments in [14]-[16].

This paper investigates the influence of the leakage flux on the SPM machine performance, which is due to the rotor permeable endcaps. The electromagnetic performance characteristics, such as the open circuit results, electromagnetic torque and torque-speed characteristics, as well as the electromagnetic losses and efficiency are predicted using 2D-FEA and 3D-FEA. A comparison between 2D and 3D-FEA results is presented and discussed. Finally, the experimental results carried out on the prototyped machine are presented to assess the validity of the design.

\section{SPM machine}

An 8-pole SPM machine, designed for an aerospace application is investigated in this study. The permanent magnets are mounted on the rotor surface in a Quasi-Halbach configuration. The retention is given by a titanium sleeve holding the magnets on a hollow shaft made of permeable 174PH stainless steel. Endcaps are designed to maintain the rotor mechanical integrity at high-speeds [17, 18]. Fig. 1 shows the cross-section of SPM machine, and Table 1 lists its main design parameters. 


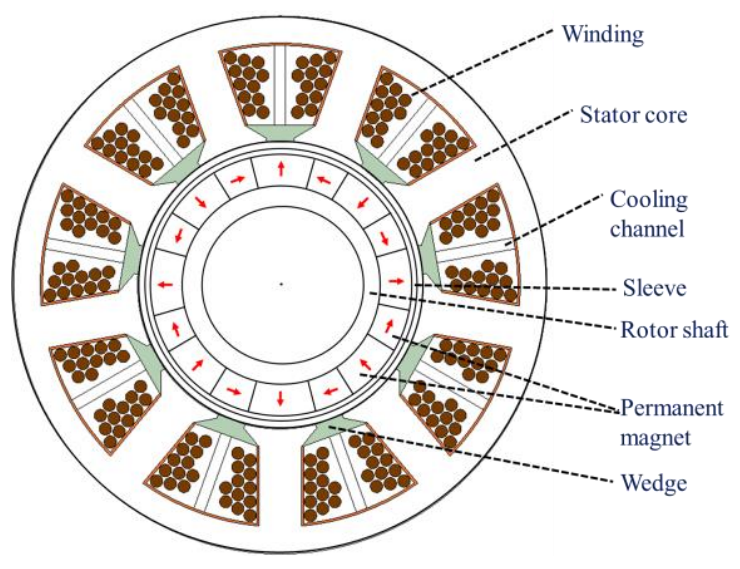

Fig. 1. Cross-section of the investigated SPM machine.

Table 1 Main design parameters of the investigated SPM machine

\begin{tabular}{lc}
\hline Parameter & Value \\
\hline Maximum speed & $19 \mathrm{krpm}$ \\
DC link voltage & $270 \mathrm{Vdc}$ \\
Maximum phase current & $85 \mathrm{~A}$ \\
Number of phases & 3 \\
Strands per turn & 4 \\
Turns per coil & 12 \\
Stack length & $80 \mathrm{~mm}$ \\
Endcap length & $2.5 \mathrm{~mm}$ \\
Airgap thickness & $0.9 \mathrm{~mm}$ \\
Sleeve thickness & $0.4 \mathrm{~mm}$ \\
Permanent magnet thickness & $4 \mathrm{~mm}$ \\
Stator outer diameter & $70 \mathrm{~mm}$ \\
Split ratio & 0.535 \\
Current density & $27.2\left(\mathrm{~A} / \mathrm{mm}^{2}\right)$ \\
\hline
\end{tabular}

The finite element (FE) model of the investigated machine has been created using the commercial package software (Infolytica MagNet). The adopted mesh used for the FE analysis is presented in Fig. 2 (a). In order to improve the accuracy of the magnetic field computation in the air-gap (being the zone with the highest energy density), it is a common practice to subdivide the main airgap into several layers with a refined mesh. Finally, 2D and 3D time-stepping simulations are considered during this study.

\section{Design consideration}

PMs are mechanically weak and brittle [19], hence a retaining sleeve is required for maintaining the circumferential stress below the yield strength of the PM material at maximum operating speed. Sleeves are normally applied with large interference fit to achieve the required retention. However, when the rotor is in standstill or at low speeds, the high interference fitted sleeve results in high compression, which axially stresses the PMs. To overcome such effect, shafts with endcaps are used to eliminate any axial strains due to the interference fitted sleeve [20].

For high-speed, low weight SPM machines a hollow shaft is often proposed to reduce the overall machine weight and rotor inertia.
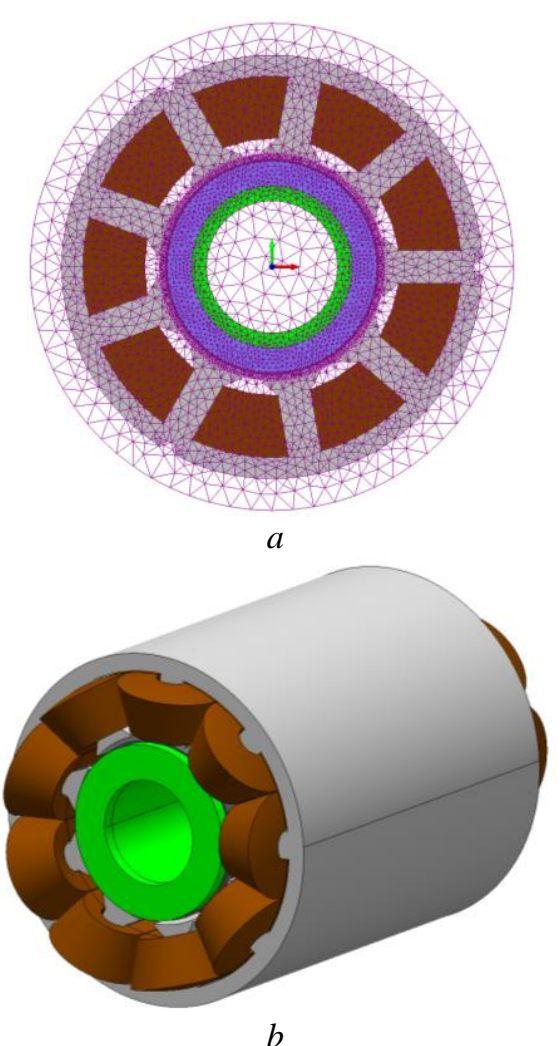

Fig. 2. FE model of the SPM machine

(a) 2D solution mesh, (b) 3D machine model

A permeable shaft is used to provide a rotor back-iron and enhance the magnetic flux production of the quasiHalbach permanent magnets. Despite the large axial length to outer diameter ratio of the motor, an end leakage flux arises, due to the permeable endcaps of the shaft [21]. Nevertheless, the torque reduction with such end leakage outweigh the torque reduction with non-permeable shaft. Table 2 presents the predicted average torque of the investigated machine with permeable and non-permeable shaft.

Table 2 Average torque of the investigated machine with permeable and non-permeable shaft computed by $2 \mathrm{D}$ - and 3D-FEA

\begin{tabular}{lcc}
\hline & $\begin{array}{c}\text { Permeable } \\
\text { shaft }\end{array}$ & $\begin{array}{c}\text { Non-permeable } \\
\text { shaft }\end{array}$ \\
\hline $\begin{array}{l}\text { Average Torque } \\
\text { (Nm), 2D-FEA }\end{array}$ & 10.52 & 9.59 \\
$\begin{array}{l}\text { Average Torque } \\
\text { (Nm), 3D-FEA }\end{array}$ & 10.08 & 9.41 \\
\hline
\end{tabular}

Adopting a non-permeable shaft, the average torque is $8.84 \%$ lower compared to permeable shaft, when computed by $2 \mathrm{D}$-FEA. Considering 3D-FEA, the torque difference between permeable and non-permeable shafts is equal to $6.64 \%$. The $3 \mathrm{D}$ value is lower than the $2 \mathrm{D}$ one, due to the endleakage in the rotor, which is properly taken into account during the 3D-FEA. Despite the end-leakage in the rotor endcaps, the obtained results prove the benefit of using a permeable shaft, since the permeable material provides a magnetic path for the PM flux, which increases the developed torque. 


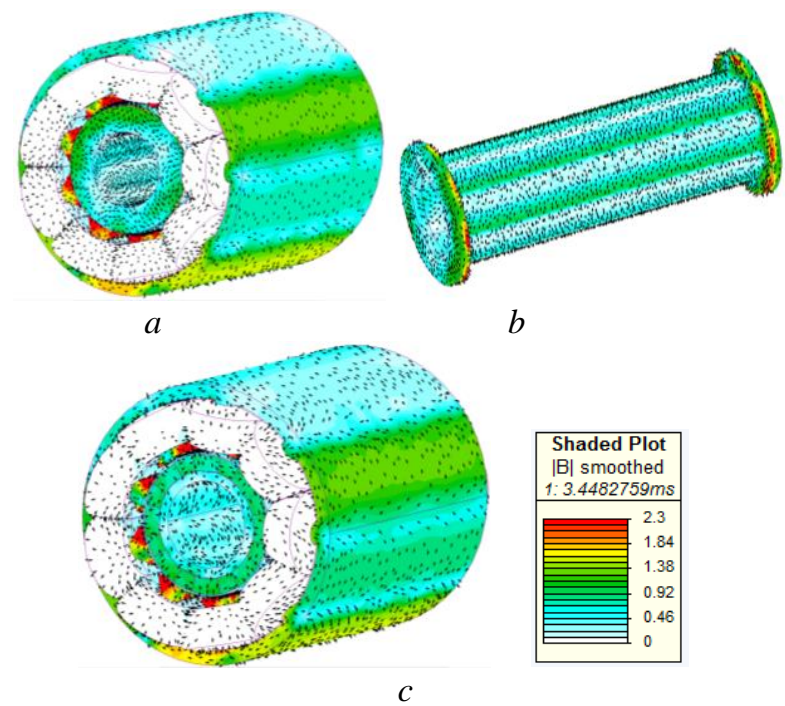

Fig. 3. Flux density distribution in the SPM machine with and without endcaps (80A, 8700rpm)

(a) SPM machine including rotor with endcaps,

(b) Permeable shaft, (c) SPM machine including without endcaps
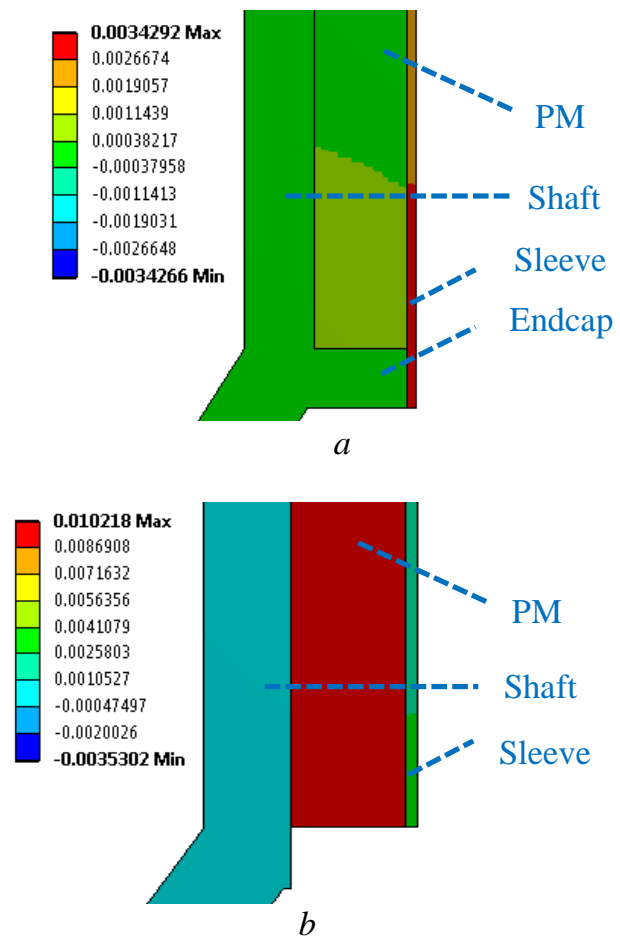

Fig. 4. Axial deformation ( $\mathrm{mm}$ ) in the SPM machine rotor with and without endcaps, sleeve interference $0.004 \mathrm{~mm}$ and rotor speed of $20 \mathrm{krpm}$

(a) Rotor with endcaps, (b) Rotor without endcaps

Fig. 3 presents the flux distribution in the SPM machine with and without rotor endcaps. A permeable shaft with non-permeable endcaps might be used for minimizing the end-leakage. However, assembling separate endcaps to the shaft is a high precision manufacturing job. Indeed, a strong fixture is required to firmly install the endcaps and misalignment needs to be avoided. Therefore, a single shaft component is preferred for manufacturing and reliability purposes. To demonstrate the benefits of the rotor endcaps, Axisymmetric FEA structural analyses have been conducted on rotor with and without endcaps.
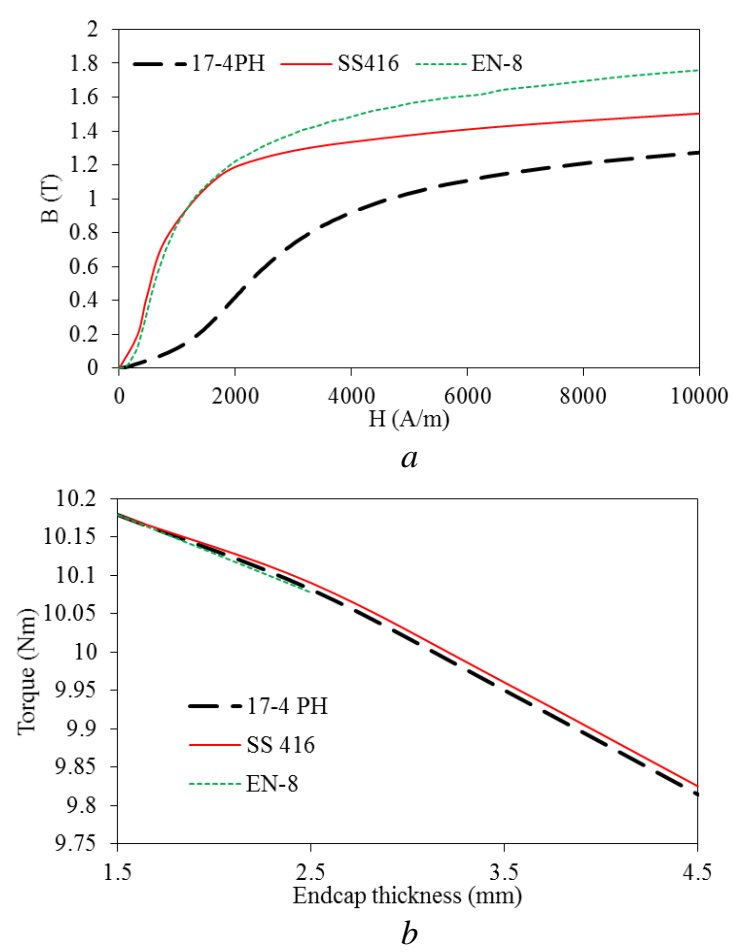

Fig. 5. The influence of different endcap material (a) B-H curves, (b) Torque versus endcap thickness

The PMs are placed around the shaft, whereas the sleeve is applied with $0.004 \mathrm{~mm}$ interference fit. Fig. 4 presents the axial deformation in the rotor with and without endcaps at 20krpm rotor speed. Axial deformation is avoided, when endcaps are included. Hence, endcaps prevent potential elastic and/or plastic deformations, which might lead to the PMs breakage during rotor assembly. It is worth noting the thickness of the endcaps does not affect the axial deformation since the mechanically stiff shaft steel provides support for the magnets even with very thin endcaps. However, relatively thick endcaps are normally selected due to manufacturability aspects.

To understand the electromagnetic aspect of the endcaps, three different magnetic steels with different B-H curves as shown in Fig. 5 (a) are investigated and compared. To ensure accuracy in terms of the considered material properties, different data sets of the $\mathrm{BH}$ curves were considered [22]. In addition, different endcap thicknesses are used to understand their influence on the electromagnetic performance. It can be seen that there is a significantly small change in the torque when the different material used for the shaft. Since the shaft provides enough magnetic path for the Quasi-Halbach magnets and the magnetic field in the endcaps are reaching the high end of the saturation. Therefore, magnetic stainless steel (17-4 PH) material which has the properties presented in Table 3 is selected for the hollow shaft.

Table 3 Material properties

\begin{tabular}{lc}
\hline $17-4$ PH Stainless Steel & Value \\
\hline Density $\left(\mathrm{kg} / \mathrm{m}^{3}\right)$ & 7820 \\
Electrical resistivity $(\Omega . \mathrm{m})$ & $7.7 \times 10^{-7}$ \\
Thermal conductivity $(\mathrm{W} /(\mathrm{m} . \mathrm{C}))$ & 19.55 \\
Yield/tensile stress $(\mathrm{MPa})$ & 1379 \\
\hline
\end{tabular}


The accuracy of the material data was confirmed using the methodologies described in [22]. When considering this configuration, the torque reduces with the thickness of the endcaps as shown in Fig. 5 (b). The percentage difference between the torque predicted by $2 \mathrm{D}-\mathrm{FEA}$ and that by $3 \mathrm{D}-\mathrm{FEA}$ for different endcap thicknesses is presented in Table 4. From the results, it can be concluded that 3D-FEA in necessary for accurate estimation despite its time consuming nature. Since the difference in torque is less than $1 \%$ between the $1.5 \mathrm{~mm}$ and $2.5 \mathrm{~mm}$ endcap thicknesses, $2.5 \mathrm{~mm}$ is selected in order to simplify the manufacturing process.

Table 4 2D- and 3D-FEA torque ratio

\begin{tabular}{lcccc}
\hline & $\begin{array}{c}1.5 \\
\mathrm{~mm}\end{array}$ & $\begin{array}{c}2.5 \\
\mathrm{~mm}\end{array}$ & $\begin{array}{c}3.5 \\
\mathrm{~mm}\end{array}$ & $\begin{array}{c}4.5 \\
\mathrm{~mm}\end{array}$ \\
\hline $\begin{array}{l}\text { 2D to 3D torque } \\
\text { percentage (\%) }\end{array}$ & 4.06 & 4.98 & 6.22 & 7.5 \\
\hline
\end{tabular}

\section{Influence of endcaps on electromagnetic performance}

\subsection{Open circuit results}

Fig. 6 (a) presents a comparison of the airgap flux density predicted by 2D-FEA and 3D-FEA. In 3D model, airgap flux density has been detected in two regions: a) at the middle of axial length and $b$ ) at one rotor end (inner edge of the front endcap). Lower amplitude and higher distortion of the airgap flux density is observed at the end of the machine, due to the influence of the end leakage. Considering the airgap flux density at the middle of the axial length, similar distribution is obtained for both 2D and 3D FEAs, although 3D-FEA distribution revels lower peaks, this is due to axial leakage in the 3D-FEA.

Likewise, lower back-EMF amplitude is found when 3D-FEA is considered as shown in Fig. 6 (b), while slightly higher total harmonic distortion (THD) is observed, as reported in Fig. 6 (c). The 1st harmonic reduction is a consequence of the end-leakage, due to the endcaps, while the higher THD is mainly given by the increase of the 3rd harmonic. In general, a double layer concentrated winding SPM machine with a 9/8 slot/pole combination inherently has a high 3rd harmonic in the back-EMF [23]. In the 2D FE analysis done here, the tooth tips of the machine are quite saturated, and this has the effect of partially suppressing the $3^{\text {rd }}$ harmonic. However, when the machine is analysed with a 3D FE model which also considers the end-effects, then this $2 \mathrm{D}$ effect is reduced and the $3^{\text {rd }}$ harmonic in the back-EMF becomes more visible.

\subsection{Electromagnetic torque}

The electromagnetic torque can be found by (1), where $N_{r}$, and $\Psi_{p m}$ are the number of pole pairs and PM flux-linkage, respectively. $L_{d}, L_{q}, I_{d}$ and $I_{q}$ are the d-and q-axis inductances and currents, respectively.

$T_{e m}=\frac{3}{2} N_{r}\left(\Psi_{p m} I_{q}+\left(L_{d}-L_{q}\right) I_{d} I_{q}\right)$

SPM machines have a small saliency ratio and hence negligible reluctance torque. Therefore, in the constant torque region, the torque is mainly a product of q-axis current and PM flux linkage.
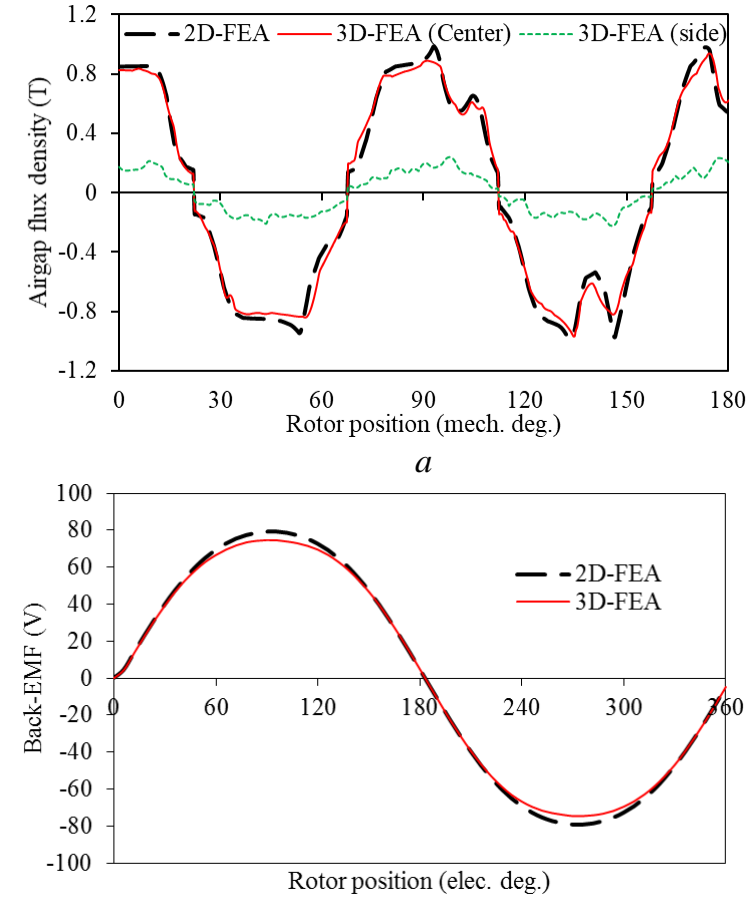

b

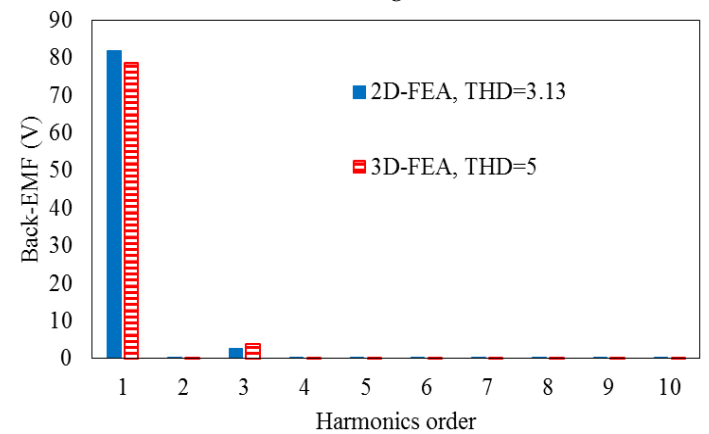

c

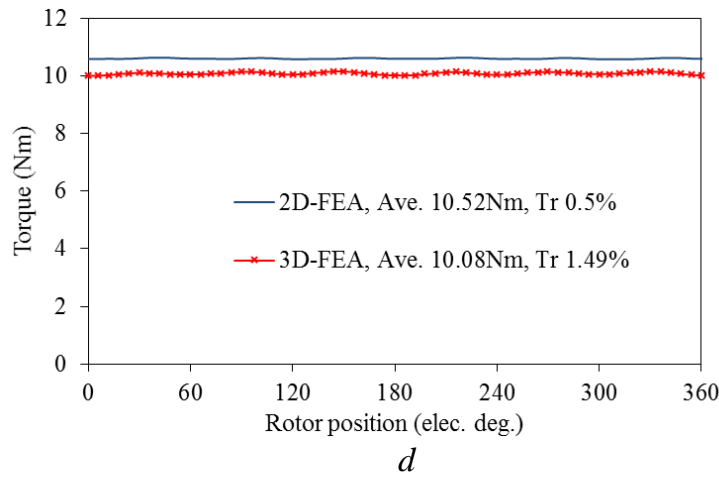

Fig. 5. Electromagnetic performance of the SPM machine with and without endcaps at $8700 \mathrm{rpm}$

(a) Airgap flux density distribution, (b) Back-EMF waveform, (c) Back-EMF waveform harmonics,

(d) Electromagnetic torque waveform

Fig. 6 (d) presents the electromagnetic torque of the SPM machine predicted by 2D-FEA and 3D-FEA, when a current of $80 \mathrm{~A}$ is applied along the q-axis, while the d-axis current is equal to zero. Since the 2D-FEA does not take into account the endcaps influence, the average torque provided by $2 \mathrm{D}-\mathrm{FEA}$ is $4.18 \%$ higher than the one determined by $3 \mathrm{D}-$ FEA. Considering the torque ripple, its value increases in the 3D-FEA, due to the higher back EMF harmonic content. 


\section{Influence of endcaps on torque-speed characteristics}

The torque speed characteristics can be found using equation (1) and (2), where $V_{p h}$ is the amplitude of phase voltage at steady state, $\omega$ is the electrical speed in rad/s and $\mathrm{Ra}$ is the phase resistance.

$V_{p h}=\sqrt{\left(R_{a} I_{d}-\omega L_{q} I_{q}\right)^{2}+\left(R_{a} I_{q}+\omega L_{d} I_{d}-\omega \Psi_{p m}\right)^{2}}$

Therefore, to determine the torque-speed characteristics the PM flux-linkage, the d-axis and q-axis inductances are predicted and analyzed. The method proposed in [24] is used to account for both magnetic saturation for PM flux-linkage and cross-coupling effects for inductances.

\subsection{PM flux linkage}

The influence of the magnetic saturation on the PM flux-linkage is investigated in this section. The magnetic flux along the d-axis $\left(\Psi_{d}\right)$ is sum of two terms, the PM flux $\left(\Psi_{p m}\right)$ and the flux produced by the d-axis current $\left(L_{d} * I_{d}\right)$.

$\Psi_{d}=\Psi_{p m}+L_{d} * I_{d}$

The variation of the d-axis flux $\left(\Psi_{d}\right)$ as function of the $\mathrm{q}$-axis current is determined by running several FE simulations at different q-axis current values, while the d-axis current is equal to zero. Since the d-axis current is null, its correspondent flux term will result equal to zero.

$\Psi_{d}\left(I_{d}=0, I_{q}\right)=\Psi_{p m}\left(I_{d}\right)$

Hence, the variation of the PM-flux with q-axis current is obtained. The described procedure has been repeated using 2D and 3D FEAs and the results are shown in Fig. 7. Due to the magnetic saturation, both PM flux-linkage values decrease as the q-axis current increases. Although this trend is common for both 2D and 3D FEAs, the PM fluxlinkage predicated via 3D-FEA reduces at faster rate compared with the 2D-FEA, due to the endcaps influence. Since, the presence of permeable rotor endcaps increases the leakage flux at the front and back ends of the rotor. This effect leads to a reduction in the flux-linkage.

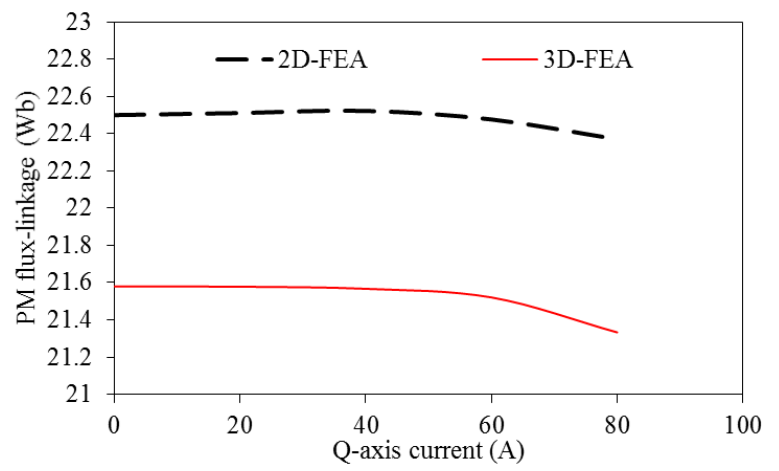

Fig. 6. PM flux-linkage at different q-axis current levels predicted by $2 D-F E A$ and $3 D-F E A$.

\subsection{Inductance}

Due to the end-windings, higher inductances are observed in the 3D-FEA compared to its 2D-FEA counterpart as shown in Table 5.
Table 5 D-axis and $\mathrm{q}$-axis inductances $(\mathrm{mH})$ at different current levels predicted by 2D-FEA and 3D-FEA

\begin{tabular}{lcc}
\hline & $\begin{array}{c}\text { D-axis inductance } \\
(2 \mathrm{D}-\mathrm{FEA})\end{array}$ & $\begin{array}{c}\text { Q-axis inductance } \\
(2 \mathrm{D}-\mathrm{FEA})\end{array}$ \\
\hline $\mathrm{I}_{\mathrm{q}}=20, \mathrm{I}_{\mathrm{d}}=-80$ & 0.276 & 0.279 \\
$\mathrm{I}_{\mathrm{q}}=40, \mathrm{I}_{\mathrm{d}}=-40$ & 0.275 & 0.274 \\
$\mathrm{I}_{\mathrm{q}}=80, \mathrm{I}_{\mathrm{d}}=-20$ & 0.266 & 0.263 \\
\hline
\end{tabular}

\begin{tabular}{lcc}
\hline & $\begin{array}{c}\text { D-axis inductance } \\
\text { (3D-FEA) }\end{array}$ & $\begin{array}{c}\text { Q-axis inductance } \\
\text { (3D-FEA) }\end{array}$ \\
\hline $\mathrm{I}_{\mathrm{q}}=20, \mathrm{I}_{\mathrm{d}}=-80$ & 0.330 & 0.329 \\
$\mathrm{I}_{\mathrm{q}}=40, \mathrm{I}_{\mathrm{d}}=-40$ & 0.331 & 0.328 \\
$\mathrm{I}_{\mathrm{q}}=80, \mathrm{I}_{\mathrm{d}}=-20$ & 0.316 & 0.318 \\
\hline
\end{tabular}

\subsection{Torque- and power-speed curves}

PM flux-linkage and inductances values obtained by means of FEA have been used for plotting both torque-speed and power-speed curves, as shown in Fig. 8.

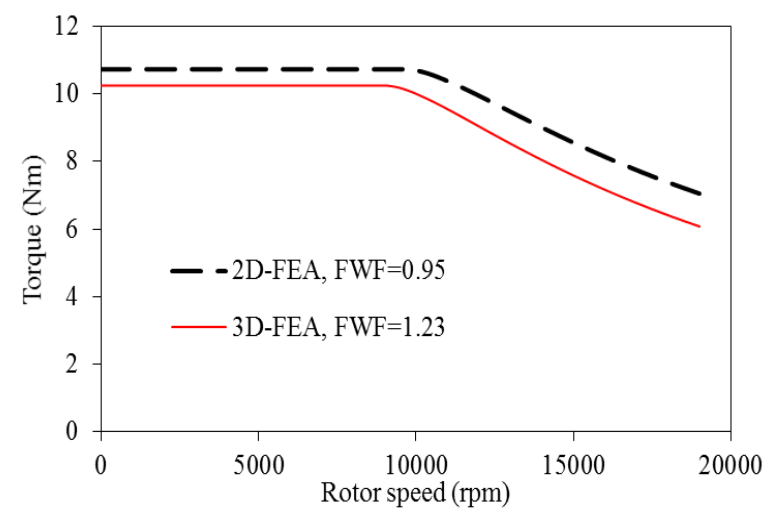

$a$

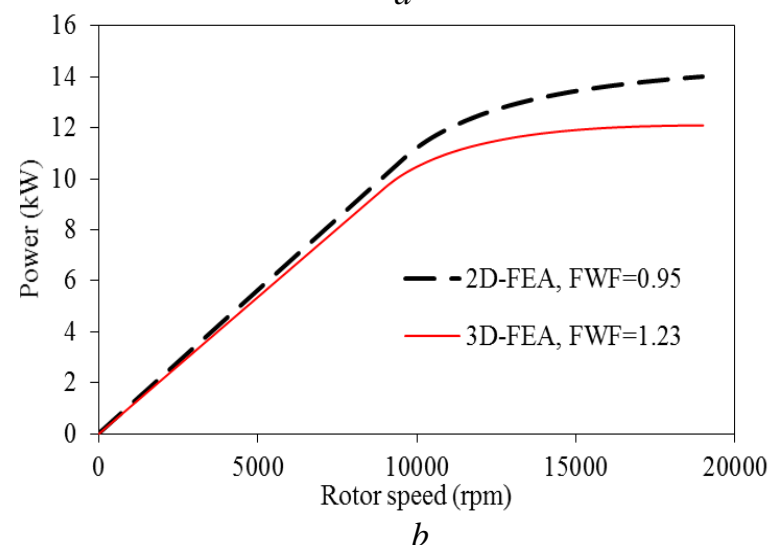

Fig. 7. Torque-speed characteristics

(a) Torque-speed curve, (b) Power-speed curve

Considering Fig. 8, 3D-FEA results provide lower torque and base speed values for the constant torque region. This outcome was expected since the PM flux-linkage predicted by 3D-FEA is lower. Additionally, a reduced power and torque can be observed in the flux weakening region. The flux weakening factor $\left(K_{f w}\right)$ has been calculated by using (5), where $I_{\max }$ is the maximum phase current [25].

$K_{f w}=\frac{L_{d} I_{\max }}{\Psi_{p m}}$ 
When 2D-FEA are used, the $K_{f w}$ is equal to 0.95 , while it boosts to 1.23 in case of 3D-FEA. The significant increase is justified by the double-action due to the low PM flux linkage and the high d-axis inductance.

\section{Influence of rotor endcaps on electromagnetic losses and efficiency}

\subsection{Copper losses}

In electrical machines, the DC copper losses can be quantified by using (6), where $I_{p h}$ is the phase current $N_{p h}$ is the number of turns per phase, $\rho_{c u}$ is the copper resistivity, $l_{c}$ is length of the coil, $A_{s}$ is the slot area, and $K_{p}$ is the packing factor.

$P_{D C}=\frac{3 I_{p h}^{2} N_{p h}^{2} \rho_{c u} l_{c}}{A_{s} K_{p}}$

On the other hand, AC copper losses component is obtained by modelling the individual strands and turns in one coil using 3D-FEA, as shown in Fig. 9 (a) and (b). The AC to DC resistance ratio at different frequencies is shown in Fig. 9 (c).

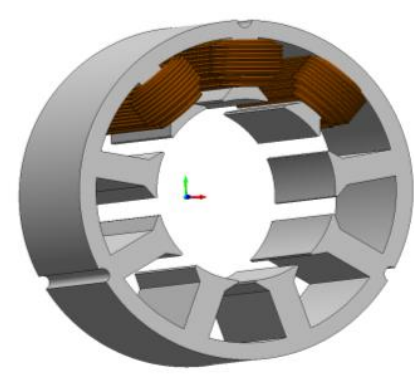

$a$

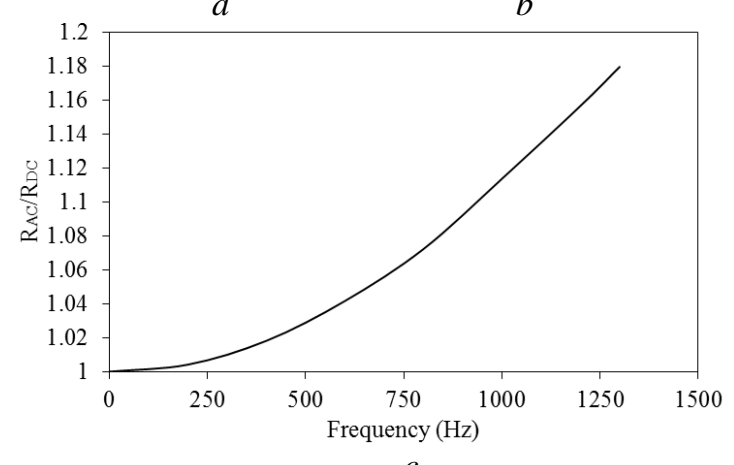

$c$

Fig. 8. AC copper loss investigation

(a) 3D-FEA model, (b) Flux density distribution in the coil, (c) $R_{A C} / R_{D C}$ ratio verses frequency

\subsection{Core losses}

Fig. 10 (a) presents the core losses of the SPM machine at rated speed of $8700 \mathrm{rpm}$ for several q-axis currents. At low current levels, i.e. below 60A, the core losses predicted by $3 \mathrm{D}$-FEA are lower than that of the 2D-FEA due to the leakage effect, which results in lower magnetic flux density in the machine core. Conversely, at higher current levels, i.e. above $60 \mathrm{~A}$, the 3D-FEA predicted core losses exceed that of the 2D-FEA [26]. This is due to the flux produced by the current flowing inside the end-windings.

\subsection{Rotor losses}

The eddy currents circulating in the conductive rotor components, i.e. PMs, retaining sleeves and shaft, generate additional losses, which can be computed by using (7), where $J_{n}$ is the eddy-current density in a conductive volume and $\sigma$ is the material conductivity.

$P_{e d d y}=\sum_{n}\left\{\int_{v o l} \frac{\left|J_{n}\right|^{2}}{2 \sigma} d v\right\}$

For each the rotor component, the eddy-current losses have been determined by using both $2 \mathrm{D}$ and 3D-FEAs. In case of 3D-FEA, two models, i.e. with and without endcaps, have been considered. Fig. 10 (b) shows the trend of the eddycurrent losses in sleeve, magnets and shaft for the three cases under study
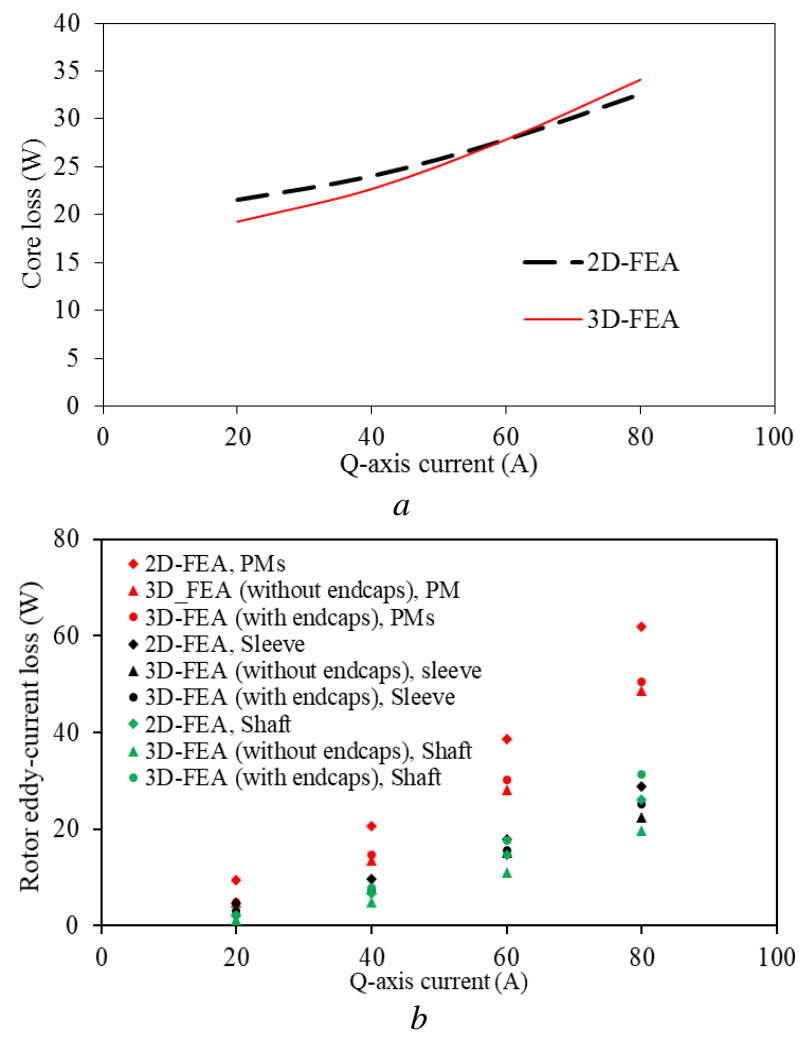

Fig. 9. Core and rotor loss at different q-axis currents (a) core loss, (b) Rotor loss

Considering the same load condition, lower eddy current losses are observed in both 3D-FEAs compared to the 2D-FEA (see Fig. 10 (b)). This is the result of lower leakage flux in 2D-FEA, which does not model end-paths and restrains the flux lines on a plan. Since a higher amount of "active" flux is considered by the 2D-FEA, the resulting eddy current losses are higher. In 3D-FEAs, lower eddy losses are obtained when the endcaps are neglected. Indeed, by including the endcaps within the model, a further circulating path for the current is added.

Although it is stated that computing the eddy-current loss in 3D-FEA might cause an increase in the rotor losses compared to the 2D-FEA since the induced current paths in the rotor will close at the end region leading to longer current path [27]. Lower eddy current losses are observed in the 3DFEA when compared to the 2D-FEA, since the rotor loss is mainly due to the high order space harmonics which has small end path compared to the rotor axial length, shown in Fig. 11. 
Additionally, the PMs span is relatively small compared to the eddy current path in the axial direction. Therefore, the reduction in the losses computed by 3D-FEA compared to the 2D-FEA due to the leaked flux is higher than the additional losses due to the eddy current at end paths of the rotor. Also, the losses in the endcaps increases at high rate with the current level, since the last determine a high stator saturation forcing the magnet flux to pass through the endcaps.

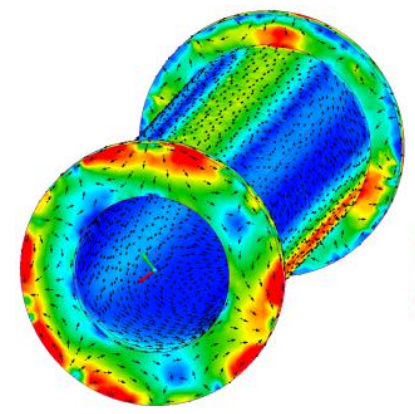

$a$

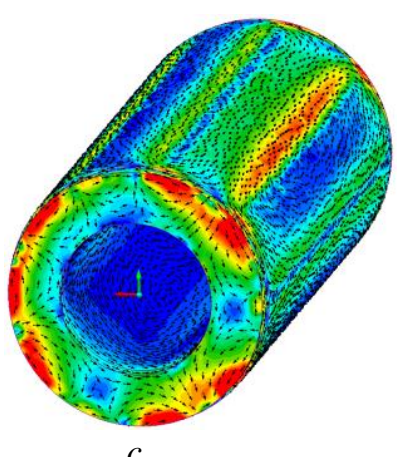

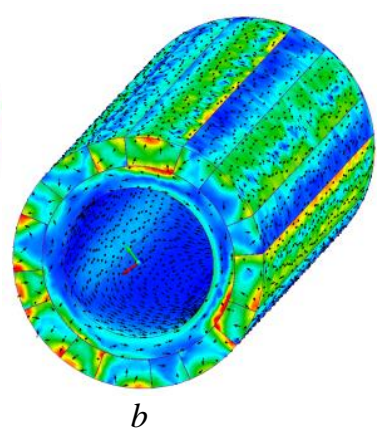

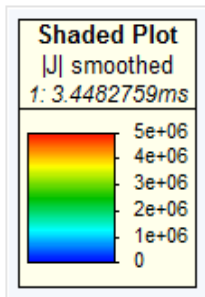

Fig. 10. Eddy-current density distribution in different rotor components

(a) Shaft and endcaps, (b) Shaft and PMs, (c) Shaft, endcaps PMs and sleeve

\subsection{SPM efficiency}

The losses terms previously predicted by FEA have been employed to determine the machine efficiency at several current and speed levels, using (8), where $P_{c u}$ is the total copper loss $\left(P_{D C}+P_{A C}\right)$ and $P_{\text {mech }}$ is the mechanical power $\left(T_{e} \Omega\right)$.

$\eta=\frac{P_{\text {mech }}}{P_{\text {mech }}+P_{\text {cu }}+P_{\text {core }}+P_{\text {eddy }}}$

The SPM efficiency results are summarized in Table 6. Due to the large amount of copper losses, the influence of the endcaps on the SPM efficiency is low despite to the reduction in the mechanical power, and changes in the core and rotor losses.

\section{Experimental validation}

According to the specifications listed in Table 1, a prototype has been manufactured and tested, in order to validate the FEA results. Fig. 12 shows the main prototype components, such as rotor, wound stator, along with the assembled machine. The test bench adopted for the experimental validation is depicted in Fig. 12 (d).
Table 6 Electromagnetic efficiency at different input conditions predicted by 2D-FEA and 3D-FEA

\begin{tabular}{lcc}
\hline Operation condition & $\begin{array}{l}\text { Efficiency } \\
\text { (2D-FEA) }\end{array}$ & $\begin{array}{c}\text { Efficiency } \\
\text { (3D-FEA) }\end{array}$ \\
\hline $\begin{array}{l}\text { 8700rpm, 20A peak current, 0 } \\
\text { current angle }\end{array}$ & 96.65 & 96.38 \\
$\begin{array}{l}\text { 8700rpm, 40A peak current, 0 } \\
\text { current angle }\end{array}$ & 95.15 & 94.2 \\
$\begin{array}{l}\text { 8700rpm, 60A peak current, 0 } \\
\text { current angle }\end{array}$ & 93.33 & 91.84 \\
$\begin{array}{l}\text { 8700rpm, 80A peak current, 0 } \\
\text { current angle }\end{array}$ & 91.47 & 89.48 \\
$\begin{array}{l}\text { 19000rpm, 80A peak current, } \\
\text { 53.5 current angle }\end{array}$ & 91.03 & 88.96 \\
\hline
\end{tabular}
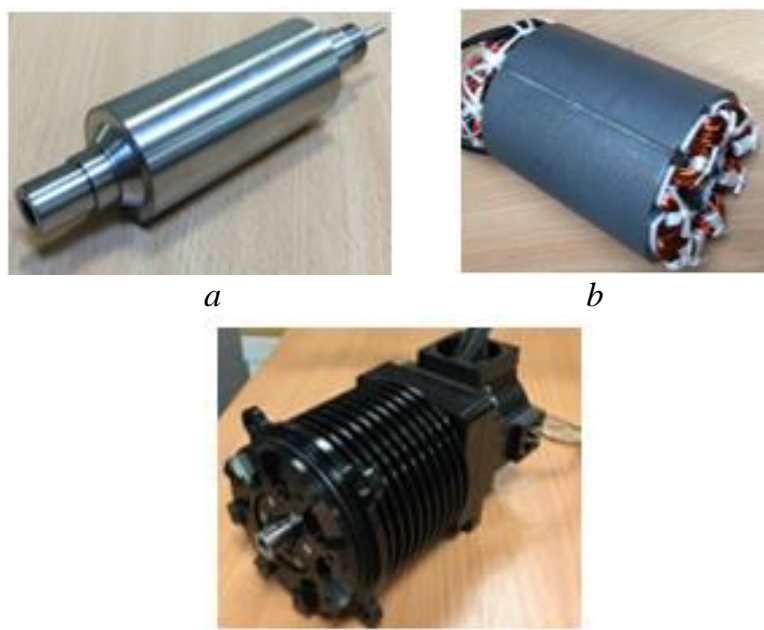

$c$

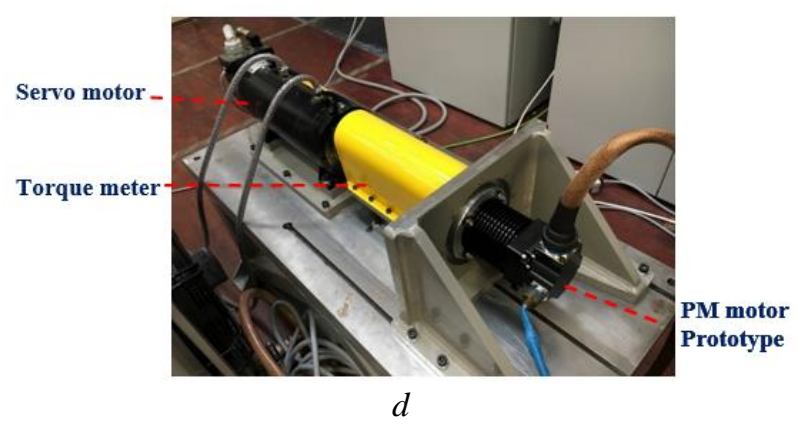

Fig. 11. SPM machine prototype

(a) Rotor assembly, (b) Stator, (c) Full assembly,

(d) Testing rig

As outcome of the no-load tests, the line to line backEMF at $19000 \mathrm{rpm}$ is reported in Fig. 13 (a), where the measured waveform is compared to the simulation results. The tested results are in good agreement with the $2 \mathrm{D}$ and $3 \mathrm{D}$ FE simulations, although the measured values of the BackEMF are slightly low at the maximum speeds with $K_{v}$ $0.0212 \mathrm{Vs} / \mathrm{rad}$. The obtained $K_{v}$ from measurements are $5.49 \%$ and $1.77 \%$ lower than the one calculated using 2D FEM and 3D FEM, respectively. Finally, the torque-current curve has been detected and compared to the FEA results, as shown in Fig. 13 (b). Based on the experimental results, the calculated torque constant with only q-axis current applied to the machine $(\mathrm{Iq}=80 \mathrm{~A}, \mathrm{Id}=0)$ is $0.123 \mathrm{Nm} / A$ which is $6.95 \%$ and $2.2 \%$ lower than the values obtained using 2D FEM and 3D FEM simulations, respectively. The measured torque is in 
good agreement with the calculated torque using FEM. A discrepancy is however noted as the current increases, leading to a difference between the measured and calculated torque. This is due to the saturation of the stator laminations which is giving higher flux leakage and due to the endcaps effect and end windings. Therefore, more accurate results could be achieved using 3D FEM which accounts for the end effects.

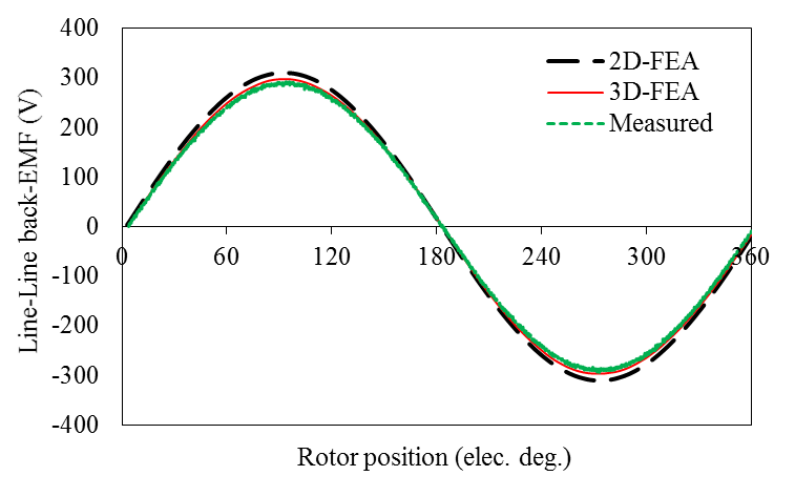

$a$

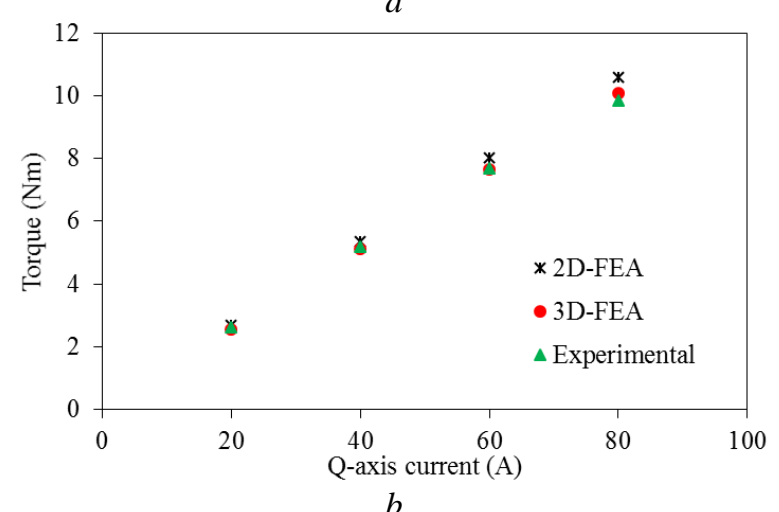

Fig. 12. Comparison between measured, and 2D-FEA and $3 D$-FEA predicted results of the investigated SPM machine

(a) Back-EMF waveform, (b) Torque-current curve

\section{Conclusion}

High-speed SPM machines require retaining sleeve and endcaps to ensure the mechanical integrity of the PMs. The effect of the endcaps has been assessed, showing a high end-effect leakage, despite the large axial length to outer diameter ratio of the machine. The influence of permeable rotor endcaps, on the electromagnetic performance of the SPM machine, is significant. When the end-effects are not taken into account, the output torque can be reduced up to $6.27 \%$, at rated current, as shown by comparison between the 2D-FEA and experimental results. A sensitivity analysis on different magnetic stainless steel materials and B-H curves, used for the hollow shaft with endcaps, is showing that the torque is not significantly affected. In conclusion, for highspeed SPM machines with permeable shaft assembly, the predicted 2D-FEA results, i.e. not taking the permeable endcaps in consideration, are insufficient to predict accurately the machine performance. The detailed 3D-FEA analysis has demonstrated how torque and power are reducing, with respect to the $2 \mathrm{D}$-FEA case, due to the inclusion of the end-effects. The extensive campaign of experimental measurement carried out on the SPM machine prototyped are validating the design, showing an excellent agreement with the 3D-FEA results, comparing back-EMF and torque with errors below $2.2 \%$.

\section{References}

[1] Gerada, D., Mebarki, A., Brown, N., Gerada, C., Cavagnino, A., Boglietti, A.: High-speed electrical machines: technologies, trends, and developments', IEEE Trans. Ind. Electronics., 2014, 61, (6), pp. 29462959.

[2] Al-Timimy, A., Degano, M., Giangrande, P., Lo Calzo, L.: 'Design and optimization of a high power density machine for flooded industrial pump', (ICEM), Lausanne, 2016, pp. 1480-1486.

[3] Wang, J., Xia, X., Howe, D.: 'Three-phase modular permanent magnet brushless machine for torque boosting on a down-seized ICE vehicles', IEEE Trans. Veh. Technol., 2005, 54, (3), pp. 809-816.

[4] El-refaie, A., Jahns, T.: 'Optimal flux-weakening in surface PM machines using concentrated windings' IEEE Trans. Ind. Applicat., 2005, 41, (3), pp. 790-800.

[5] Vagati, A., Pellegrino, G., Guglielmi, P.: 'Comparison between SPM and IPM motor drives for EV applications', (ICEM), Rome, 2010, pp. 1-6.

[6] Wang, J., Yuan, X., Atallah, K.: 'Design optimization of a surface-mounted permanent -magnet motor with concentrated windings for electric vehicle applications', IEEE Trans. Veh. Technol., 2013, 62, (3), pp. 1053-1064.

[7] Azzouzi, J., Barakat, G., Dakyo, B.: 'Quasi-3-D analytical modeling of the magnetic field of an axial flux permanent-magnet synchronous machine', IEEE Trans. Energy Convers., 2005, 20, (4), pp. 746-752.

[8] Platen, M., Henneberger, G.,: 'Examination of leakage and end effects in a linear synchronous motor for vertical transportation by means of finite element computation', IEEE Trans. Mag., 2008, 37, (5), pp. 3640-3643.

[9] Yu, C., Zhu, Z., Howe, D.,: 'Three-dimensional lumpedparameter magnetic circuit analysis of single-phase fluxswitching permanent-magnet motor', IEEE Trans. Mag., 2008, 44, (6), pp. 1701-1710.

[10] Sanada, M., Morimoto, S., Takeda, Y.: 'Interior permanent magnet linear synchronous motor for highperformance drives' IEEE Trans. Ind. Applicat., 1997, 33, (4), pp. 966-972.

[11] Polinder, H., Slootweg, J., Hoeijmakers, M., Compter, J.: 'Modeling of a liner PM machine including magnetic saturation and end effects: maximum force-to-current ratio ' IEEE Trans. Ind. Applicat., 2003, 39, (6), pp. 1681-1688.

[12] Hua, W., Cheng, M., Zhu, X., Zhang, J.: 'Investigation of end-effect in brushless machines having magnets in the stator with doubly salient structure ', IEEE Int. Magn. Conf., 2006, pp. 197.

[13]Zhu, X., Cheng, M., Hua, W., Zhang, J.: 'Investigation of end-effect and experimental validation for hybrid excited doubly salient machine ', $12^{\text {th }}$ biennial IEEE conference, 2006, pp. 320.

[14]Zhu, Z., Chen, J., Pang, Y., Howe, D., Iwasaki, S., Deodhar, R.: 'Modeling of end-effect in flux-switching permanent magnet machines ', Int. Conf. Elec. Mach. Syst, 2007, pp. 943-948.

[15]Zhu, Z., Pang, Y., Hua, W., Cheng, M., Howe, D.: ' Investigation of end effect in permanent magnet 
brushless machines having magnets on the stator' J. Appl. Phys., 2006, 99, (8), pp. 319-323.

[16]Zhu, Z., Azar, Z.: 'Influence of end-effect and crosscoupling on torque-speed characteristics of switched flux permanent magnet machines', 8th Int. Conf. Power Electron., 2011, pp. 145-152.

[17] Al-Timimy, A., Degano, M., Xu, Z., Lo Calzo, L. Giangrande, P., Galea, M. Gerada, C., Zhang, H., Xia, L.: 'Trade-off analysis and design of a high power density PM machine for flooded industrial pump', (IECON), Florence, 2016, pp. 1749-1754.

[18] Xu, Z., Al-Timimy, A., Degano, M., Giangrande, P., Lo Calzo, L., Zhang, H., Galea, M., Gerada, C., Pickering, S., Xia, L.: 'Thermal management of a permanent magnet motor for a directly coupled pump', (ICEM), Lausanne, 2016, pp. 2738-2744.

[19] Galea, M., Gerada, C., Raminosoa, T., and Wheeler, P.: 'Design of a high force density tubular permanent magnet motor,' in Electrical Machines (ICEM), 2010, XIX International Conference on, 2010, pp. 1-6..

[20] Barrans, S., Al-ani, M., Carter, J.: 'Mechanical design of rotors for permanent magnet high-speed electric motors for turbocharger applications ' IEEE Trans. Elect. Systems in Transportation, 2017.

[21] Al-ani, M., Zhu, Z.: 'Influence of end-effect on torquespeed characteristics of various switched flux permanent magnet machine topologies' COMPEL, 2015, 35, (2), pp. 525-539.

[22] Mohammed, A. M., Cox, T., Galea, M., and Gerada, C.: 'A New Method for determining the Magnetic Properties of Solid Materials employed in Unconventional Magnetic Circuits,' IEEE Transactions on Industrial Electronics, vol. 64, iss.3, pp. 2468 - 2475, 2017.

[23] Hanselman, Duane C. Brushless permanent magnet motor design. The Writers' Collective, 2003..

[24] Qi, G., Chen, J., Zhu, Z., Howe, D., Zhou, L., Gu, C.: Influence of skew and cross-coupling on fluxweakening performance of permanent-magnet brushless AC machines ', IEEE Trans. Mag., 2009, 45, (5), pp. 2110-2117.

[25] Soong, W., Miller, T.: 'Field-weakening performance of brushless synchronous AC motor drive ', IEE Porc. Elect. Power Appl., 1994, 141, (6), pp. 331-340.

[26] Silva, V., Meunier, G. Foggia, A.: 'A 3D fininte-element computation of eddy currents losses in the stator end lamination of large synchronous machines ', IEEE Trans. Mag., 1996, 32, (3), pp. 1569-1572.

[27] Van Der Veen, J., Offringa, L., Vandenput, A.: 'Minimizing rotor losses in high-speed high-power permanent magnet synchronous generators with rectifier load ', IEE Porc. Elect. Power Appl., 1997, 144, (5), pp. 331-3337. 